\title{
Clinical and genetic predictors of weight gain in patients diagnosed with breast cancer
}

\section{Citation}

Reddy, S M, M Sadim, J Li, N Yi, S Agarwal, C S Mantzoros, and V G Kaklamani. 2013. “Clinical and genetic predictors of weight gain in patients diagnosed with breast cancer." British Journal of Cancer 109 (4): 872-881. doi:10.1038/bjc.2013.441. http://dx.doi.org/10.1038/bjc.2013.441.

\section{Published Version}

doi:10.1038/bjc.2013.441

\section{Permanent link}

http://nrs.harvard.edu/urn-3:HUL.InstRepos:12785934

\section{Terms of Use}

This article was downloaded from Harvard University's DASH repository, and is made available under the terms and conditions applicable to Other Posted Material, as set forth at http:// nrs.harvard.edu/urn-3:HUL.InstRepos:dash.current.terms-of-use\#LAA

\section{Share Your Story}

The Harvard community has made this article openly available.

Please share how this access benefits you. Submit a story.

\section{Accessibility}




\title{
Clinical and genetic predictors of weight gain in patients diagnosed with breast cancer
}

\author{
S M Reddy ${ }^{1}, \mathrm{M} \mathrm{Sadim}^{2}, \mathrm{~J} \mathrm{Li}^{3}, \mathrm{~N} \mathrm{Yi}{ }^{3}, \mathrm{~S} \mathrm{Agarwal}^{2}, \mathrm{C} \mathrm{S} \mathrm{Mantzoros}^{4}$ and V G Kaklamani ${ }^{\star 2}$ \\ ${ }^{1}$ Department of Medicine, Feinberg School of Medicine, Northwestern University, Chicago, IL, USA; ${ }^{2}$ Division of Hematology/ \\ Oncology, Department of Medicine, Northwestern University, Chicago, IL, USA; ${ }^{3}$ Department of Biostatistics, University \\ of Alabama, Birmingham, AL, USA and ${ }^{4}$ Division of Endocrinology, Department of Medicine, Harvard Medical School, Boston, \\ MA, USA
}

Background: Post-diagnosis weight gain in breast cancer patients has been associated with increased cancer recurrence and mortality. Our study was designed to identify risk factors for this weight gain and create a predictive model to identify a high-risk population for targeted interventions.

Methods: Chart review was conducted on 459 breast cancer patients from Northwestern Robert H. Lurie Cancer Centre to obtain weights and body mass indices (BMls) over an 18-month period from diagnosis. We also recorded tumour characteristics, demographics, clinical factors, and treatment regimens. Blood samples were genotyped for 14 single-nucleotide polymorphisms (SNPs) in fat mass and obesity-associated protein (FTO) and adiponectin pathway genes (ADIPOQ and ADIPOR1).

Results: In all, $56 \%$ of patients had $>0.5 \mathrm{~kg} \mathrm{~m}^{-2}$ increase in BMI from diagnosis to 18 months, with average BMl and weight gain of $1.9 \mathrm{~kg} \mathrm{~m}^{-2}$ and $5.1 \mathrm{~kg}$, respectively. Our best predictive model was a primarily SNP-based model incorporating all 14 FTO and adiponectin pathway SNPs studied, their epistatic interactions, and age and BMI at diagnosis, with area under receiver operating characteristic curve of 0.85 for 18 -month weight gain.

Conclusion: We created a powerful risk prediction model that can identify breast cancer patients at high risk for weight gain.

In contrast to other malignancies, many patients diagnosed with breast cancer gain weight after diagnosis. A recent review of the literature from 1997 to 2009 showed that $34 \%-100 \%$ of patients gained weight post-diagnosis, and mean weight gain ranged from 0.27 to $7.3 \mathrm{~kg}$ over follow-up period ranging from 6 months to 5 years (Vance et al, 2011), values that are higher than in the general population (Williamson et al, 1991; Williamson, 1993). This is especially significant in the breast cancer population as obesity at diagnosis (Chlebowski et al, 2002; Kroenke et al, 2005; Loi et al, 2005; Litton et al, 2008; Vance et al, 2011) and weight gain after diagnosis (Camoriano et al, 1990; Chlebowski et al, 2002; Kroenke et al, 2005) have both been shown to be associated with poor prognosis, including increased cancer recurrence, decreased overall and breast cancer-associated survival, and decreased response to chemotherapy in addition to decreased quality of life.
Studies have shown an association of clinical variables with this weight gain, including baseline age and body mass index (BMI), treatment factors such as chemotherapy and hormone therapy, tumour characteristics such as stage, and menopausal status, but with conflicting findings (Camoriano et al, 1990; Kumar et al, 1997; Demark-Wahnefried et al, 1997a,b; Aslani et al, 1999; Day et al, 1999; Goodwin et al, 1999; Kutynec et al, 1999; Costa et al, 2002; Lankester et al, 2002; Rock and Demark-Wahnefried, 2002; Freedman et al, 2004; Ingram and Brown, 2004; Irwin et al, 2005; Kroenke et al, 2005; Caan et al, 2006; Campbell et al, 2007; Saquib et al, 2007; Han et al, 2009; Heideman et al, 2009; Gu et al, 2010). In the general population, there is an important genetic background that contributes to obesity and weight gain (Fox et al, 2005; Silventoinen and Kaprio, 2009). FTO, fat mass and obesityassociated protein, was recently found in genome-wide association studies (GWAS) to be associated with obesity and is a protein 
predominantly expressed in the hypothalamus and cerebellum. It is thought to mediate its effect on weight by decreasing satiety and activity levels (Hinney et al, 2007; Rampersaud et al, 2008; Wardle et al, 2008). We previously published a case-control study showing that FTO is expressed in both normal and malignant breast tissue and that FTO polymorphisms are associated with breast cancer risk (Kaklamani et al, 2011a). Adiponectin is an endogenous insulin sensitiser that regulates the secretion of insulin-like growth factor, oestrogens, and tumour necrosis factor, and along with its receptors has also been shown to be associated with weight gain as well as diabetes and cardiovascular disease (Menzaghi et al, 2002; Stumvoll et al, 2002; Ukkola et al, 2005; Yang and Chuang, 2006; Loos et al, 2007; Edwards et al, 2012). We have also previously published data linking polymorphisms in the adiponectin gene (ADIPOQ) and its receptor (ADIPOR1) to breast cancer risk (Kaklamani et al, 2008a). To our knowledge, no studies have investigated the effects of genetic variables on weight gain after breast cancer diagnosis.

The purpose of our study is to investigate the contribution to post-diagnosis weight gain of genetic polymorphisms in FTO, ADIPOQ, and ADIPOR1, clinical variables, and gene $\times$ environment interactions in breast cancer patients. By developing and comparing various predictive models, we aim to create a risk prediction tool that can be used clinically to isolate a high-risk patient population for targeted weight loss interventions.

\section{MATERIALS AND METHODS}

Study participants. Patients were recruited from the medical oncology clinics at Robert H Lurie Comprehensive Cancer Centre from August 2007 to December 2009. All patients signed an informed consent for study participation and for genetic studies, and the protocol was approved by the Institutional Review Board of Northwestern University. Inclusion criteria included diagnosis of stages I-III breast cancer, age $\geqslant 18$ years, and female sex. Exclusion criteria included presence of in situ only cancer, metastatic disease, pregnancy, or poorly controlled diseases that can independently results in weight changes such as thyroid disease or systemic infection.

Chart review. A retrospective chart review was conducted on recruited patients to obtain weights and BMIs over an 18-month period from diagnosis, tumour characteristics (ER/PR/HER2 status, grade, presence of lymph node metastases, stage), demographics (age, race), clinical factors (menopausal status), treatment regimens (chemotherapy use and type, endocrine therapy use and type, radiation use), family history of breast or ovarian cancer, and any evidence of recurrence. Anthropometric variables were measured in our outpatient clinic by trained staff. If weights were not available within 2 months of the desired time point, data were recorded as missing.

DNA isolation. Blood samples were collected for genotyping of polymorphisms in FTO, ADIPOQ, and ADIPOR1. DNA from whole blood lymphocytes was extracted using the QIAamp DNA Blood Mini Kit (Qiagen, Hilden, Germany) and was stored at $-20^{\circ} \mathrm{C}$ until use for genotyping.

Selection of SNPs. ADIPOQ has $>10$ single-nucleotide polymorphisms (SNPs; Hara et al, 2002; Vasseur et al, 2002) and two linkage disequilibrium (LD) blocks with a block boundary between -2049 and -450 (Menzaghi et al, 2002). We selected to genotype haplotype tagging SNPs rs266729 (5' flanking region), rs822396 (intron 1), and rs822395 (intron 1) to tag block 1 and rs150129 (exon 2) and rs2241766 (intron 2) to tag block 2 as these are the five most common SNPs and have been studied more extensively by others as to their functionality and relation to diseases such as diabetes mellitus (Hara et al, 2002; Menzaghi et al, 2002; Filippi et al, 2005; Heid et al, 2006). ADIPOR1 has > 28 SNPs and two LD blocks (Soccio et al, 2006). One block extends from the $5^{\prime}$ flanking region to intron 4 and the other is located at the $3^{\prime}$ end of the gene. Based on this, we selected five common haplotype tagging SNPs for genotyping. For block 1, we selected the following tagging SNPs: rss2232853 ( $5^{\prime}$ flanking region), rs12733285 (intron 1), and rs134238 (intron 4). For block 2, we selected rs7539542 (exon 8 ) and rs10920531 ( $3^{\prime}$ flanking region). These SNPs were selected because they correspond to both LD blocks. All selected SNPs have been previously studied in relation to breast cancer risk by our group (Kaklamani et al, 2008a).

We selected four SNPs in FTO to evaluate. These SNPs were selected based on previous data from GWAS (Hinney et al, 2007; Grant et al, 2008; Thorleifsson et al, 2009) as well as our own published data on their association with breast cancer risk (Kaklamani et al, 2011a). More specifically, rs9939609 has been previously identified to be significantly associated with obesity and diabetes mellitus (Grant et al, 2008; van Hoek et al, 2008; Thorleifsson et al, 2009; Zhao et al, 2009). Furthermore, other SNPs in the same LD block (rs1121980, rs9939973, rs7193144, rs9940128, and rs8050136) were found to be associated with obesity (Hinney et al, 2007). The SNPs we selected to evaluate are all in intron 1 of FTO and represent LD block 6 (rs7206790 and rs8047395) and LD block 7 (rs9939609 and rs1477196).

Genotyping. Genotyping for the 14 SNPs was performed by Taqman SNP allelic discrimination by means of an ABI 7900HT (Applied Biosystems, Forest City, CA, USA). Results were ascertained by using the SDS software version 2.3 (Applied Biosystems). All results were automatically called (i.e., the device displays the genotypes automatically with a $95 \%$ certainty). A total of $5 \%$ of samples were genotyped in duplicate and showed $100 \%$ concordance. A total of 31 of the 459 patients had missing blood samples so these patients were not included in the genetic analyses.

Statistical analysis. Data were first analysed descriptively to determine whether or not any missing values and outliers exist. Hardy-Weinberg equilibrium was checked for each SNP. Generalised linear models were implemented to explore the relationship between the weight change and SNPs or covariates, both in a singleSNP or single-covariate analysis and in a multiple-SNP analysis.

In the multiple-SNP analysis, we considered an epistatic model in which the main effects of SNPs as well as their possible epistatic interactions were fitted in the model. The purpose of including epistatic interactions in a model is to understand how the effect of a SNP depends on the presence or absence of another SNP, and to aid discovery of some SNPs that affect the weight change mainly through their epistatic effects. For both the single-SNP and multiple-SNP analyses, we studied the influence of SNPs on the weight change adjusted for the covariates that are statistically significant in the single-covariate analysis.

To facilitate the analysis of epistatic interactions in a model, we used the Cockerham genetic model to encode the main effects of SNPs. We denoted the common homozygote (i.e., the homozygote of a SNP with a higher frequency), heterozygote, and rare homozygote for each SNP by $c, h$, and $r$, respectively. The Cockerham model defines two main effects for each SNP, an additive contrast as $-1,0$, and 1 for $c, h$, and $r$, and a dominance contrast as -0.5 for $c$ and $r$ and 0.5 for $h$, respectively (Cordell, 2002; Kao and Zeng, 2002). The additive effect represents the genotypic effect $(r-c) / 2$, and the dominance effect measures $h-(c+r) / 2$ in the probability of being cases. A positive additive effect indicates that the rare homozygote increases the possibility of weight change compared with the common homozygote, and a positive dominance effect means that the heterozygote increases the possibility of weight change compared with the mean of two homozygotes. Accordingly, the epistatic predictors are constructed 
by multiplying two corresponding main effects of SNPs, introducing four epistatic interactions for a pair of SNPs, that is, additive-additive, additive-dominance, dominance-additive, and dominance-dominance interactions.

For the covariates, we encoded binary exposure as 0 and 1 , and standardised other exposures to have a mean of 0 and a s.d. of 0.5 . This scaling scheme puts continuous variables on the same scale as symmetric binary variables.

We used the Bayesian hierarchical normal linear model (Lake et al, 2003; Becker et al, 2005; Kwee et al, 2007; Hein et al, 2009) because the classical normal linear models have problems such as nonidentifiability of parameters, computational inefficiency, and limited statistical power for detecting causal variants when there are a large number of genetic factors and interactions, even if highly correlated (Lake et al, 2003; Becker et al, 2005; Kwee et al, 2007; Hein et al, 2009). This Bayesian model can overcome these problems mainly by placing some appropriate prior distributions on parameters. Specifically, we assume independent Student's $t$ priors, $t_{v_{j}}\left(0, s_{j}^{2}\right)$, on parameters in the model. We are motivated to use the $t$ distribution because it can produce robust inference, shrinkage estimation, and easy computation (Gelman et al, 2008; Yi and Xu, 2008; Yi and Banerjee, 2009). The $t$ distribution can be expressed as a mixture of normal distributions with mean 0 and variance distributed as scaled inverse- $\chi^{2}$

$$
\beta_{\mathrm{j}}\left|\tau_{\mathrm{j}}^{2} \sim N\left(0, \tau_{\mathrm{j}}^{2}\right), \tau_{\mathrm{j}}^{2}\right| s_{\mathrm{j}}^{2} \sim \operatorname{Inv}-\chi^{2}\left(v_{\mathrm{j}}, s_{\mathrm{j}}^{2}\right), j=1, \ldots, \mathbf{J},
$$

where $J$ is the total number of parameters and $\beta_{j}$ is the $j$ th parameter in the model, and the hyperparameters $v_{j}$ and $s_{j}$ can be predetermined reasonably. For the main effects, we set $\left(v_{j}, s_{j}\right)=(1,2.5)$. For epistatic interactions, we set $\left(v_{\mathrm{j}}, s_{\mathrm{j}}\right)=\left(1,2.5 k_{\mathrm{G}} / k_{\mathrm{GG}}\right)$, where $k_{\mathrm{G}}$ and $k_{\mathrm{GG}}$ are the total numbers of main and epistatic interaction effects of SNPs, respectively. These priors apply more stringent restrictions on interactions. We fitted our hierarchical normal linear models by incorporating an expectation-maximisation algorithm into the usual iteratively weighted least squares for classical normal linear models.

To explore the factors that influence the higher and lower BMI changes, we conducted a quartile analysis. To this end, we first divided BMI change into four equal groups and select a sub-data set in which the patients have BMI change in the lower $(\leqslant 25 \%)$ and upper $(\geqslant 75 \%)$ quartiles. We then encoded BMI change in the lower quartile as 0 and the upper quartile as 1 . Given this data, we re-run the statistical analyses described above and used odds ratio (OR) to measure the effect sizes of SNPs and covariates of interest on the BMI change.

To make model selection and interpretation of results more proper, we compared and contrasted the deviance and the Akaike information criterion (AIC) between different models. The deviance, defined as -2 times the log-likelihood, is a measure of goodness of fit; smaller deviance means better fit to data. AIC, defined as deviance plus 2 times the number of predictors, measures the predictive power; a model is estimated to reduce outof-sample prediction error if AIC decreases.

To assess the predictive accuracy of our models for weight gain, we performed receiver operating characteristics (ROCs) analysis, including estimation of true-positive rate (also known as sensitivity) and false-positive rate (i.e., 1 - specificity), estimation of an ROC curve, and computing the area under the ROC curve (AUC). We conducted the analysis based on the two models: main effect model and epistatic model.

\section{RESULTS}

Baseline characteristics. Of the 562 patients initially enrolled in the study, 459 had adequate data to be included in our analysis. Of the 103 patients who were not included in the analysis, only 5 were lost to follow-up. Twenty-seven of the patients not included met exclusion criteria that were missed on initial recruitment: 15 had metastatic cancer, 5 had ductal carcinoma in situ, 2 had lobular carcinoma in situ, 3 were pregnant, and 2 had a concurrent malignancy. The remaining patients had missing weight data either at baseline or on follow-up that precluded data analysis.

Table 1 highlights the baseline patient characteristics and Table 2 the treatment characteristics of the 459 patients included in our analyses. The average patient age was 51.3 (s.d. 10.9) years old with the majority being Caucasian (74.5\%) and the most common minority population being African American. The mean baseline BMI was $27.5 \mathrm{~kg} \mathrm{~m}^{-2}$, classified in the overweight category, and mean baseline weight $74.2 \mathrm{~kg}$. About $70 \%$ of the patients received chemotherapy and radiation therapy, with the most common chemotherapy regimen being doxorubicin at $60 \mathrm{mg} \mathrm{m}^{-2}$ and cyclophosphamide at $600 \mathrm{mg} \mathrm{m}^{-2}$ i.v. every 2 weeks for four cycles followed by paclitaxel at $175 \mathrm{mg} \mathrm{m}^{-2}$ every 2 weeks for four cycles (ddACT), and $78 \%$ received endocrine therapy with tamoxifen being the most commonly used agent. Supplementary Table 1 shows the distribution of SNP alleles for the 4 FTO and 10 adiponectin pathway polymorphisms being evaluated in this study along with allele frequencies. In all, $<1 \%$ of the SNP data are listed as undetermined, indicating that the analyser was unable to determine the specific allele; each of these samples was run twice for confirmation.

Weight gain. As seen in Table 3,33\% of patients at 6 months and $56 \%$ at 18 months had a BMI increase of $>0.5 \mathrm{~kg} \mathrm{~m}^{-2}$ from baseline. Average weight gain among these patients was $3.5 \mathrm{~kg}$ (s.d. $2.36 \mathrm{~kg}$ ) at 6 month and $5.1 \mathrm{~kg}$ (s.d. $3.76 \mathrm{~kg}$ ) at 18 -month follow-up, with corresponding BMI increases from $1.3 \mathrm{~kg} \mathrm{~m}^{-2}$ (s.d. $0.84 \mathrm{~kg} \mathrm{~m}^{-2}$ ) to $1.9 \mathrm{~kg} \mathrm{~m}^{-2}$ (s.d. $1.42 \mathrm{~kg} \mathrm{~m}^{-2}$ ). To better evaluate clinically significant weight gain, we looked at $>5 \%$ increase in baseline BMI and found that $13 \%$ of patients at 6 months and $36 \%$ at 18 months had gained this amount of weight. The maximum BMI increase was $9 \mathrm{~kg} \mathrm{~m}^{-2}$ at 18 months ( $38 \%$ increase in BMI), with maximum weight increase of $23.4 \mathrm{~kg}$.

Univariate analysis of clinical variables. Supplementary Table 2 shows the significant clinical variables in the univariate analysis at each time point of 6,12 , and 18 months from breast cancer diagnosis. Results for our analyses are expressed in effect sizes, with each value quantifying the relative change in BMI with variable of interest, for example -0.106 for BMI at diagnosis indicating that each additional increase in BMI by $1 \mathrm{~kg} \mathrm{~m}^{-2}$ at diagnosis is associated with $0.106 \mathrm{~kg} \mathrm{~m}^{-2}$ less increase in BMI by 6 months. Quartile analysis data is also included and expressed as ORs comparing likelihood of being in the upper quartile of weight gain compared with lower quartile with variable of interest. Results show that BMI at diagnosis and age were both negatively correlated with weight gain with younger and lower weight patients being at higher risk of weight gain. Weight gain was also associated with lower stage, ER/PR-positive markers, use of endocrine therapy, and absence of chemotherapy. Among the chemotherapy regimens, docetaxel $75 \mathrm{mg} \mathrm{m}^{-2}$ and cyclophosphamide $600 \mathrm{mg} \mathrm{m}^{-2}$ (TC) i.v. every 3 weeks for four cycles was associated with less weight gain. There was some support for weight gain with premenopausal status at diagnosis (weight gain associated with premenopausal $>$ postmenopausal $>$ perimenopausal), menopausal change from premenopausal to peri/postmenopausal, absence of lymph node metastases, lower tumour grade, tamoxifen use, and white race though results were not significant across all time points. It should be noted that menopause classification was obtained from what was labelled in chart review and not based on serum markers. Menopausal status was more clearly specified in the diagnosis history and physical notes but at 1 year was only mentioned clearly in some patients' charts and in other cases postmenopausal status 


\begin{tabular}{|c|c|}
\hline & Mean (range) \\
\hline $\begin{array}{l}\text { Age (years) } \\
\text { BMl at diagnosis }\left(\mathrm{kg} \mathrm{m}^{-2}\right) \\
\text { Weight at diagnosis }(\mathrm{kg})\end{array}$ & $\begin{array}{c}51.3(26-84) \\
27.5(14.9-51.9) \\
74.2(36.4-144.1)\end{array}$ \\
\hline & $N(\%)$ \\
\hline \multicolumn{2}{|l|}{ Race } \\
\hline $\begin{array}{l}\text { Caucasian } \\
\text { African American } \\
\text { Asian } \\
\text { Hispanic } \\
\text { Unknown }\end{array}$ & $\begin{array}{c}342(74.5) \\
68(14.8) \\
22(4.8) \\
20(4.4) \\
7(1.5)\end{array}$ \\
\hline
\end{tabular}

\begin{tabular}{|l|c|}
\hline \multicolumn{2}{|l|}{ Stage at diagnosis } \\
\hline II \\
III \\
Unknown & $158(34.4)$ \\
\hline Lymph node metastases & $194(42.3)$ \\
& $106(23.1)$ \\
\hline+ & $1(<0.1)$ \\
\hline & \\
\hline Unknown & $232(50.5)$ \\
\hline Tumour grade & $217(47.3)$ \\
\hline 1 & $10(2.2)$ \\
2 & \\
3 & $84(18.3)$ \\
Unknown & $196(42.7)$ \\
\hline
\end{tabular}

\begin{tabular}{|c|c|}
\hline \multicolumn{2}{|c|}{ ER status } \\
\hline $\begin{array}{l}+ \\
-\end{array}$ & $\begin{array}{c}367(80.0) \\
92(20.0)\end{array}$ \\
\hline \multicolumn{2}{|c|}{ PR status } \\
\hline $\begin{array}{l}+ \\
- \\
\text { Unknown }\end{array}$ & $\begin{array}{c}323(70.4) \\
132(28.8) \\
4(0.9)\end{array}$ \\
\hline \multicolumn{2}{|c|}{ Her2 status } \\
\hline $\begin{array}{l}+ \\
- \\
\text { Unknown }\end{array}$ & $\begin{array}{c}78(17.0) \\
366(79.7) \\
14(3.3)\end{array}$ \\
\hline
\end{tabular}

\section{Menopause at diagnosis}

\begin{tabular}{|l|c|}
\hline Premenopausal & $222(48.4)$ \\
Perimenopausal & $22(4.8)$ \\
Postmenopausal & $204(44.4)$ \\
Unknown & $11(2.4)$
\end{tabular}

\section{Menopause at 1 year}

\begin{tabular}{|l|c|}
\hline Premenopausal & $112(24.4)$ \\
Perimenopausal & $31(6.8)$ \\
Postmenopausal & $272(59.3)$ \\
Unknown & $44(9.6)$
\end{tabular}

\section{Family history}

\begin{tabular}{|l|c|}
\hline+ & $194(42.3)$ \\
- & $254(55.3)$ \\
Unknown & $11(2.4)$ \\
\hline
\end{tabular}

Abbreviation: $\mathrm{BMI}=$ body mass index; $; \mathrm{ER}=$ estrogen receptor; $\mathrm{PR}=$ progesterone receptor.

\section{Table 2. Baseline treatment characteristics}

\begin{tabular}{|c|c|}
\hline & $\mathbf{N}(\%)$ \\
\hline \multicolumn{2}{|l|}{ Radiation } \\
\hline $\begin{array}{l}+ \\
- \\
\text { Unknown }\end{array}$ & $\begin{array}{c}322(70.2) \\
131(28.5) \\
6(1.3)\end{array}$ \\
\hline \multicolumn{2}{|l|}{ Chemotherapy } \\
\hline $\begin{array}{l}+ \\
-\end{array}$ & $\begin{array}{l}325(70.8) \\
134(29.2)\end{array}$ \\
\hline \multicolumn{2}{|l|}{ Type of chemotherapy } \\
\hline $\begin{array}{l}\text { AC } \times 4 \\
\mathrm{TC} \times 4 \\
\text { Anthracycline }+ \text { taxane chemotherapy } \\
\text { Other }^{\mathbf{b}}\end{array}$ & $\begin{array}{r}66(20.3) \\
23(7.1) \\
194(59.7) \\
42(12.9)\end{array}$ \\
\hline \multicolumn{2}{|l|}{ Endocrine therapy } \\
\hline $\begin{array}{l}+ \\
- \\
\text { Unknown }\end{array}$ & $\begin{aligned} 359 & (78.2) \\
99 & (21.6) \\
1 & (0.2)\end{aligned}$ \\
\hline \multicolumn{2}{|l|}{ Type of endocrine therapy } \\
\hline $\begin{array}{l}\text { Tamoxifen } \times 5 \text { years } \\
\text { Aromatase inhibitor } \times 5 \text { years } \\
\text { Tamoxifen } \times 5 \text { years followed by aromatase inhibitor } \\
\text { Unknown or other }\end{array}$ & $\begin{array}{c}150(41.8) \\
134(37.3) \\
72(20.1) \\
9(2.5)\end{array}$ \\
\hline \multicolumn{2}{|c|}{ 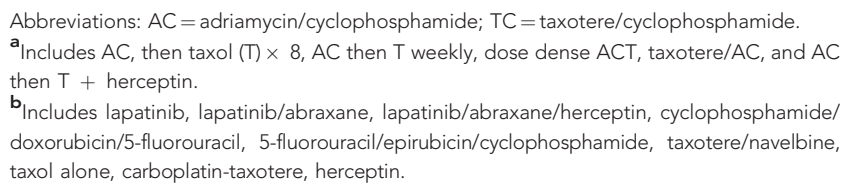 } \\
\hline
\end{tabular}

was inferred from descriptions of no menses for $>1$ year. Given the lack of thorough charting in follow-up notes, approximately $10 \%$ of 1 -year data on menopausal status are missing, as can be seen in Table 1 . No statistically significant differences in weight gain were seen at any time points for radiation therapy, family history, HER2 status, or menopausal status at 1 year.

Single SNP analysis. Single SNP analyses were conducted using a generalised linear model with effect sizes and quartile analyses with ORs, adjusting for clinical covariates. Results are as shown in Table 4. One FTO SNP (rs7206790) and six adiponectin pathway SNPs (rs1342387, rs822396, rs2232853, rs1501299, rs7539542, and rs10920531) were found through additive or dominance effects to be associated with weight gain for at least one time point, with the adiponectin rs822396 SNP through additive effects being the only one to show significance at two time points.

Multivariate analysis. We used the Bayesian hierarchical generalised linear model for our multivariate analysis. This was performed using both epistatic and non-epistatic models as well as models including the FTO SNPs alone, the adiponectin pathway SNPs alone, and a combination of both sets of SNPs. The epistatic model using both sets of SNPs showed the best fit with smallest deviance and so was chosen to interpret our results as shown in Table 5. Also included are the results of multivariate quartile analysis. Paying particular attention to the SNPs that are significant at the 12-month or final 18-month points either individually or part of an interaction, rs822396, rs266729, rs1342387, and rs7539542 are notable. For the clinical variables, age and BMI were again significant across multiple time points (though age lost significance 
Table 3. Weight changes in patient population

\begin{tabular}{|c|c|c|c|}
\hline & 6 Months & 12 Months & 18 Months \\
\hline Average BMI (weight) change & $0.07 \mathrm{~kg} \mathrm{~m}^{-2}(0.3 \mathrm{~kg})$ & $0.32 \mathrm{~kg} \mathrm{~m}^{-2}(1.0 \mathrm{~kg})$ & $0.56 \mathrm{~kg} \mathrm{~m}^{-2}(1.9 \mathrm{~kg})$ \\
\hline$\%$ Of patients with $>0.5 \mathrm{~kg} \mathrm{~m}^{-2} \uparrow \mathrm{BMI}$ & $33.0 \%$ & $49.0 \%$ & $56.0 \%$ \\
\hline Average BMI (weight) increase ${ }^{a}$ & $1.3 \mathrm{~kg} \mathrm{~m}^{-2}(3.5 \mathrm{~kg})$ & $1.6 \mathrm{~kg} \mathrm{~m}^{-2}(4.4 \mathrm{~kg})$ & $1.9 \mathrm{~kg} \mathrm{~m}^{-2}(5.1 \mathrm{~kg})$ \\
\hline$\%$ Of patients with $>5 \% \uparrow \mathrm{BMI}$ & $13.0 \%$ & $27.0 \%$ & $36.0 \%$ \\
\hline Average BMI (weight) increase ${ }^{\mathbf{b}}$ & $2.0 \mathrm{~kg} \mathrm{~m}^{-2}(5.5 \mathrm{~kg})$ & $2.3 \mathrm{~kg} \mathrm{~m}^{-2}(6.1 \mathrm{~kg})$ & $2.5 \mathrm{~kg} \mathrm{~m}^{-2}(6.7 \mathrm{~kg})$ \\
\hline Maximum BMI \% $\uparrow$ & $18.0 \%$ & $31.0 \%$ & $38.0 \%$ \\
\hline Maximum BMI (weight) $\uparrow$ & $5.0 \mathrm{~kg} \mathrm{~m}^{-2}(15.1 \mathrm{~kg})$ & $6.4 \mathrm{~kg} \mathrm{~m}^{-2}(16.5 \mathrm{~kg})$ & $9.0 \mathrm{~kg} \mathrm{~m}^{-2}(23.5 \mathrm{~kg})$ \\
\hline \multicolumn{4}{|l|}{$\begin{array}{l}\text { Abbreviation: } \mathrm{BMI}=\text { body mass index. } \\
{ }^{\mathrm{a}} \text { Among patients with }>0.5 \mathrm{~kg} \mathrm{~m}^{-2} \uparrow \mathrm{BMI} \\
\mathrm{b}_{\text {Among patients with }}>5 \% \uparrow \mathrm{BMI}\end{array}$} \\
\hline
\end{tabular}

Table 4. Significant SNPs in single SNP analyses ${ }^{\mathrm{a}, \mathrm{b}}$

\begin{tabular}{|l|c|c|c|}
\hline & $\begin{array}{c}\text { 6 Months } \\
\text { (effect size }\end{array}$ & $\begin{array}{c}12 \text { Months } \\
\text { (effect size) }\end{array}$ & $\begin{array}{c}18 \text { Months } \\
\text { (effect size) }\end{array}$ \\
\hline ADIPOQ rs822396a & & $0.186^{\star \star}$ & $0.208^{\star \star}$ \\
\hline ADIPOR1 rs2232853d & & $0.122^{\star}$ & \\
\hline ADIPOQ rs1501299a & & $-0.108^{\star}$ & \\
\hline FTO rs7206790d & & & $-0.112^{\star}$ \\
\hline ADIPOR1 rs7539542a & & & $-0.114^{\star \star}$ \\
\hline ADIPOR1 rs7539542d & & & $0.117^{\star}$ \\
\hline ADIPOR1 rs10920531a & & & $-0.077^{\star}$ \\
\hline & & &
\end{tabular}

Abbreviations: $\mathrm{BMI}=$ body mass index; $\mathrm{SNP}=$ single-nucleotide polymorphism. ${ }^{\star} P<0.05$, $\star \star P<0.01$

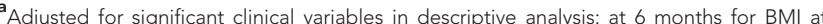
diagnosis, age, race, stage, lymph node metastases, estrogen receptor status, progesterone receptor status, chemotherapy, and hormone therapy; at 1 year for $\mathrm{BMI}$ at diagnosis, age, stage, estrogen receptor status, menopause status at diagnosis, chemotherapy, and hormone therapy; at 18 months for $\mathrm{BMl}$ at diagnosis, race, estrogen receptor status, menopause status at diagnosis, menopause transition from pre to postmenopausal at 1 year, and hormone therapy. Quartile analyses were adjusted for all clinical variables at each time point.

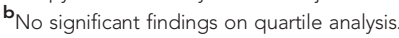

${ }^{{ }}$Effect size defined as difference in BMI gain with presence of the variable of interest. Positive values denote relative increase in BMI gain by that quantity. Negative values denote relative decrease in $\mathrm{BMI}$ gain by that quantity.

at 18 months) with younger and lower BMI women being at higher risk for weight gain, consistent with our univariate analysis. Oestrogen receptor status positivity, absence of chemotherapy, and lower stage were also associated with increased weight gain, although stage was only significant at the 6-month time point.

Predictive models. We created several clinical, genetic, and combination models using the above data to predict the postdiagnosis weight gain in our patients. As described in the Materials and Methods section, discriminatory power of our predictive models was assessed by performing ROC analysis (Figure 1). The ROC curves show the estimated true-positive and the false-positive rates for different classification thresholds between 0 and 1 . The AUC represents the probability that given two random individuals, one who will develop the disease and the other who will not, the predictive model will assign the former as a positive test and the latter as a negative test. A perfect predictive model would have an AUC of 1. It has been suggested that an AUC $>0.5$ has some discriminatory ability and for screening high-risk individuals an AUC $>0.75$ should be used (Janssens et al, 2007).

A traditional clinical model was generated with the significant variables on univariate analysis and yielded AUCs of 0.51, 0.50, and 0.47 for 6,12 , and 18 -month weight gains, respectively. For the genetic SNP models, analyses were conducted on both main effect and epistatic models for FTO SNPs alone, adiponectin pathway SNPs alone, and the combination of both at each time point. We performed the analyses first by focusing on only the significant SNPs seen in the above multivariate analysis and then by including all the SNPs. We found that an epistatic model incorporating all 14 SNPs had highest AUCs with values of 0.84, 0.81, and 0.79 for 6, 12 , and 18-month weight gains, respectively. In comparison, the epistatic model incorporating only significant SNPs had AUCs of $0.57,0.59$, and 0.24 and the main effects model with all 14 SNPs had AUCs of 0.6, 0.6, and 0.59. Incorporating both FTO and adiponectin pathway SNPs yielded higher AUC values than including only one of these groups. Using our most predictive model of all 14 SNPs and their epistatic interactions, we analysed several combinations with clinical variables and found that incorporating all significant clinical variables decreased the AUCs to values of $0.55,0.48$, and 0.52 . In contrast, addition of only the baseline age and BMI yielded our most powerful model, as illustrated in Figure 1, with AUC values of $0.90,0.88$, and 0.85 , for 6,12 , and 18-month weight gains, respectively.

\section{DISCUSSION}

Using a retrospective cohort analysis of 459 breast cancer patients, we were able to construct a primarily SNP-based predictive model with high discriminatory power for post-diagnosis weight gain. We tested multiple predictive models, including a traditional clinical model, genetic model using FTO and adiponectin pathway SNPs, and combination models, and we found that a model incorporating all 14 SNPs (from FTO, ADIPOQ, and ADIPOR1) studied in addition to their epistatic interactions and baseline age and BMI was most predictive of weight gain with AUC as high as 0.90 for 6month weight gain and 0.85 for 18 -month weight gain.

In creating these models, we initially evaluated for specific polymorphisms \pm epistatic interactions with significant associations to weight gain as highlighted in Tables 4 and 5. Notably, rs822396 (ADIPOQ) was statistically significant across our different genetic analyses presented - linear univariate analysis, multivariate analysis, and quartile analyses. We previously showed this polymorphism contributes to risk of prostate and colon cancer and other groups have shown increased risk of type 2 diabetes and ischaemic stroke (Hegener et al, 2006; Kaklamani et al, 2008b, 2011b; Mtiraoui et al, 2012), but this is the first published correlation to post-diagnosis weight gain in breast cancer patients. The other SNPs listed in the multivariate analysis were less consistently significant across different analyses and time points. 
Table 5. Multivariate analysis using Bayesian hierarchical generalised linear model

\begin{tabular}{|c|c|c|c|c|c|c|}
\hline & $\begin{array}{c}6 \text { Months } \\
\left(\text { effect size }{ }^{a}\right)\end{array}$ & $\begin{array}{l}12 \text { Months } \\
\text { (effect size) }\end{array}$ & $\begin{array}{l}18 \text { Months } \\
\text { (effect size) }\end{array}$ & $\begin{array}{l}\text { Quartile analysis } \\
\text { at } 6 \text { months (OR) }\end{array}$ & $\begin{array}{l}\text { Quartile analysis at } \\
12 \text { months (OR) }\end{array}$ & $\begin{array}{l}\text { Quartile analysis } \\
\text { at } 18 \text { months (OR) }\end{array}$ \\
\hline Age & $-0.144^{\star}$ & $-0.110^{\star \star}$ & & & & \\
\hline $\mathrm{BMI}$ at diagnosis & & $-0.083^{*}$ & $-0.140^{\star \star}$ & & & \\
\hline Stages II vs III & $0.117^{\star}$ & & & & & \\
\hline Chemotherapy & $-0.179^{\star \star}$ & $-0.097^{\star}$ & & & & \\
\hline ER positive & $0.223^{*}$ & $0.134^{\star \star}$ & $0.224^{\star \star}$ & & & \\
\hline Grades 2 vs 3 & & & & & & $0.158^{*}$ \\
\hline rs7206790a & $-0.082^{\star}$ & & & & & \\
\hline rs8047395a & $0.078^{*}$ & & & & & \\
\hline rs1501299a & $-0.112^{\star \star}$ & & & & & \\
\hline rs10920531a × rs822396a & $-0.100^{\star *}$ & & & & & \\
\hline rs12733285d $\times$ rs1501299a & $-0.228^{\star \star}$ & & & & & \\
\hline rs12733285d $\times$ rs9939609d & $-0.314^{\star \star}$ & & & & & \\
\hline rs1342387d & & $-0.104^{\star \star}$ & & & & \\
\hline rs266729d & & $-0.994^{\star \star}$ & & & & \\
\hline rs1342387d $\times$ rs266729d & & $-0.209^{\star *}$ & & & & \\
\hline $\mathrm{rs} 266729 \mathrm{~d} \times \mathrm{rs} 7539542 \mathrm{~d}$ & & & $0.466^{\star \star}$ & & & \\
\hline rs822396a & & & & & & $0.236^{*}$ \\
\hline \multicolumn{7}{|c|}{ 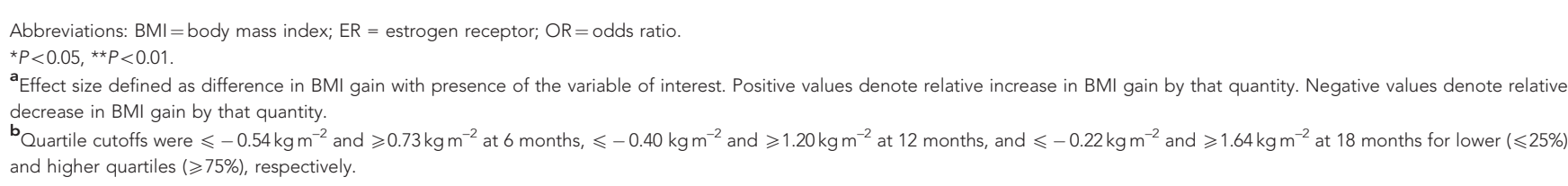 } \\
\hline
\end{tabular}
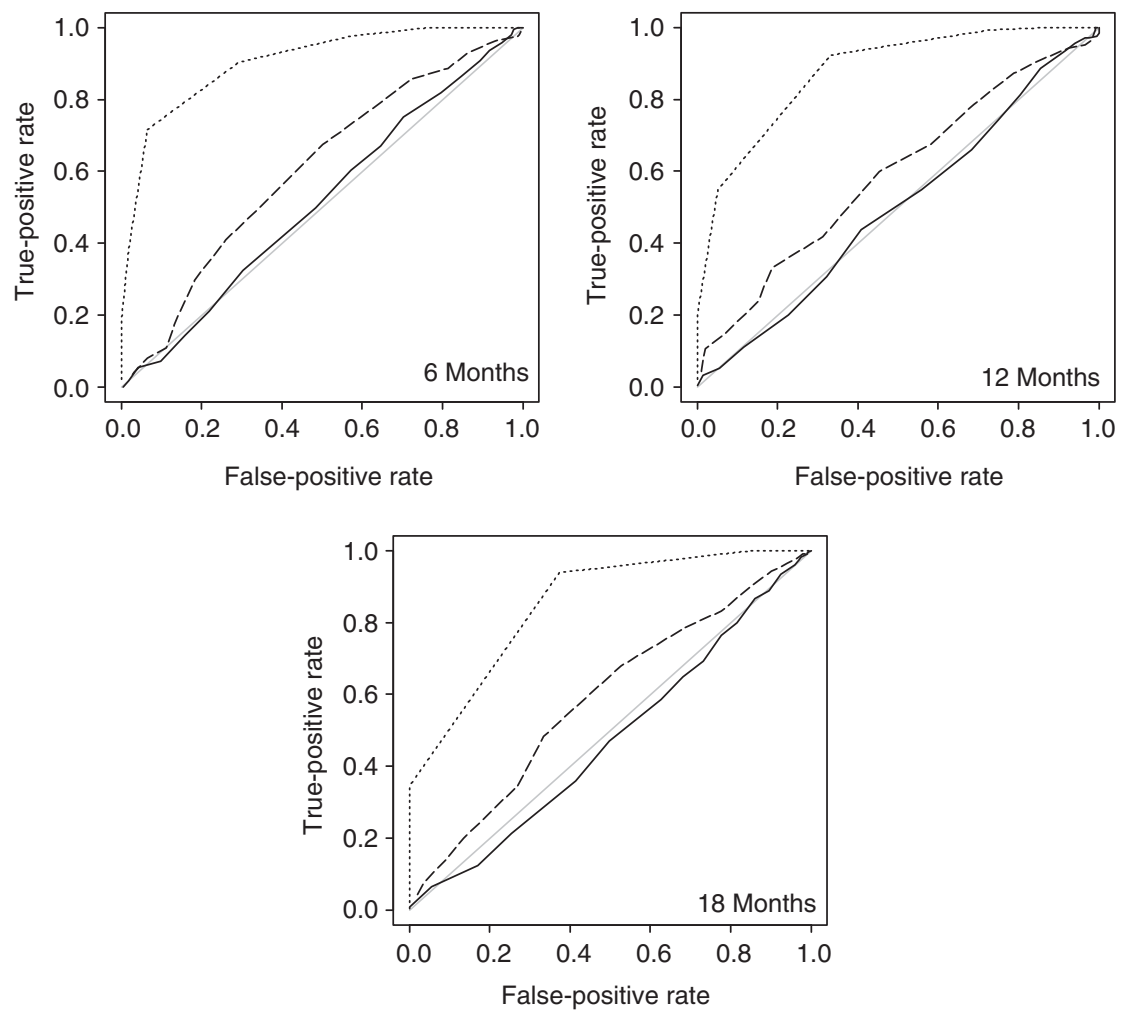

Figure 1. ROC curves at 6,12 , and 18 months. Solid line indicates ROC curve for the significant clinical variable model (AUC $=0.51$ at 6 months, 0.50 at 12 months, and 0.47 at 18 months), dashed line indicates ROC curve for the 14 SNPs model (AUC $=0.60$ at 6 months, 0.59 at 12 months, and 0.58 at 18 months), and dotted line indicates ROC curve for the 14 SNPs + epistatic interactions + age + BMI at diagnosis model (AUC $=0.90$ at 6 months, 0.88 at 12 months, and 0.85 at 18 months). The grey line represents AUC of 0.5 . 
Aside from rs822396, the other significant genetic findings at 12or 18-month time points were interactions among rs266729 (ADIPOQ), rs1342387 (ADIPOR1), and rs7539542 (ADIPOR1). In addition to also having associations with risk of prostate and colon cancer, type 2 diabetes, and ischaemic stroke, these SNPs have been linked to coronary artery disease, hypertension, and efficacy of weight loss products such as sibutramine (Hegener et al, 2006; Siitonen et al, 2006; Kaklamani et al, 2008b; Hsiao et al, 2010; Han et al, 2011; He et al, 2011; Liu et al, 2011; Kaklamani et al, 2011b; Mather et al, 2012; Mtiraoui et al, 2012; Yang et al, 2012; Zhang et al, 2012). Receiver operating characteristic analysis of an epistatic model of significant SNPs on multivariate analysis only showed AUC of 0.24 for 18 -month weight gain. When the models were expanded to include all 14 SNPs, this value increased to 0.79 , highlighting the loss of discriminatory power with limiting analysis to only selected SNPs; of note, analysis with only the 10 adiponectin pathway SNPs or the 4 FTO SNPs yielded lower AUC values as well.

To create a clinical predictive model and isolate variables for a combined genetic and clinical model, we assessed various demographic and clinical variables. We found that younger patients and those with lower BMI at diagnosis are more likely to gain weight, which is consistent with other studies (Rock and Demark-Wahnefried, 2002; Irwin et al, 2005; Kroenke et al, 2005; Caan et al, 2006; Saquib et al, 2007; Gu et al, 2010). Although there was a general trend that Hispanics gained more weight than whites who gained more weight than Asians and African Americans, this was not shown to be significant in our analyses.

In terms of treatment factors, chemotherapy was actually associated with decreased weight gain in multivariate analysis at 6- and 12-month time points and lost significance at the final 18 -month time point. Historically, chemotherapy has been thought to contribute to weight gain as seen in many prior studies (Rock and Demark-Wahnefried, 2002; Kroenke et al, 2005; Caan et al, 2006; Saquib et al, 2007; Heideman et al, 2009; Gu et al, 2010). Several studies have contradicted this and proposed that the shorter duration regimens that are now used such as TC regimens do not cause this weight gain (Demark-Wahnefried et al, 1997a; Kutynec et al, 1999; Freedman et al, 2004; Ingram and Brown, 2004). As seen in Table 1, the majority of our patients received adriamycin/cyclophosphamide, TC, or ddACT regimens as opposed to the longer FEC and CMF regimens, which are included in the 'other' category.

Effect of menopausal status has been conflicting in the literature with the majority of reports showing increased weight gain with premenopausal status (Camoriano et al, 1990; Rock and DemarkWahnefried, 2002; Caan et al, 2006; Campbell et al, 2007; Heideman et al, 2009) or absence of effect (Aslani et al, 1999; Costa et al, 2002; Lankester et al, 2002; Han et al, 2009) and the minority showing weight gain with postmenopausal status (Irwin et al, 2005). Our study showed premenopausal status at diagnosis was associated with weight gain in univariate analysis but after adjusting for other significant clinical variables as well as SNPs, found no significant difference. Consistent with some other studies, we showed that the subset of patients who underwent transition from premenopausal status at diagnosis to postmenopausal at 1 year gained weight (Goodwin et al, 1999; Campbell et $a l, 2007)$ although this too lost significance in multivariate analysis. It is important to mention that the menopausal status was gathered from chart review and was not based on objective evaluation. This chart review process likely decreased the accuracy of menopausal status categorisation, in particular decreasing the frequency of patients assigned as 'postmenopausal' at 1 year or 'perimenopausal' at either time point. It is possible that this limited our power to find a relationship between premenopausal to postmenopausal transition at 1 year and post-diagnosis weight gain.
With respect to tumour characteristics, our study interestingly found that oestrogen receptor positivity was found to be associated with weight gain at each time point in both the univariate and multivariate analyses. This association has only been weakly demonstrated in the literature (Goodwin et al, 1999) with most studies finding no correlation (Camoriano et al, 1990; Han et al, 2009; Gu et al, 2010). Further studies will need to continue exploring hormone receptor status as a causative factor. We did not find strong consistent correlations for other tumour characteristics. Lower stage tumours were associated with weight gain at 6 months but lost significance by 12 months and lymph node metastases were not found to be significant at any time point. Similarly, low-grade tumours were only significant at 18 months by quartile analysis, which is a less robust statistical analysis than the linear model using effect sizes. More of the literature supports weight gain with higher stage tumours (Demark-Wahnefried et al, 1997b; Goodwin et al, 1999; Irwin et al, 2005; Gu et al, 2010) but there is also contradictory literature (Rock and DemarkWahnefried, 2002; Kroenke et al, 2005).

We created a predictive clinical model incorporating significant findings and found an AUC of only 0.47 at 18 -month time point, indicating the generally low discriminatory ability of the clinical variables and perhaps explaining the conflicting findings in the literature for the majority of these variables. We also created combination models with the 14 SNPs and their epistatic interactions as the base and found that adding all the significant covariates decreased the AUC from 0.79 at 18 months to 0.52 . The model, however, was enhanced by adding only baseline age and BMI with resulting AUC of 0.85 . This combination model of 4 FTO SNPs +10 adiponectin pathway SNPs + epistatic interactions + baseline age + baseline BMI was therefore our optimal model with highest predictive power.

Our study has several strengths and limitations. One limitation of this retrospective cohort study is that the weights were obtained by chart review. However, although weight was not measured on a standardised scale at each visit, it was still measured during clinic visits as opposed to via patient self-reporting, so it is unclear how much this affected the results if at all. We excluded weight data that were not within 2 months of our desired time points, thereby maximising accuracy of our measurements. We are currently conducting a prospective study of 300 breast cancer patients who will be weighed at 6-month intervals in a controlled setting to better address this limitation. As mentioned above, menopausal status, especially at 1 year, may also have been inaccurate because of the retrospective nature of this study. Another limitation is that the study design did not have a control group of matched nonbreast cancer patients to compare weight gain trends and the predictive role of the polymorphisms and clinical variables studied. Although this data would have been interesting, it is not clinically relevant as post-breast cancer diagnosis weight gain, irrespective of what proportion is secondary to the breast cancer diagnosis and subsequent treatments, is associated with poor outcomes and needs to be minimised. The median age of our patients is lower than that of the United States (Gloeckler Ries et al, 2003). However, previous published work from our group includes patients of similar demographics (Kaklamani et al, 2008a; Kaklamani et al, 2011a) depicting the patient population seen in our centre. We do not believe that this impacts on our results. The strengths of our study are the large number of patients included in the cohort and the combination analysis of clinical and genetic characteristics.

This is the first study to evaluate the effects of genetic polymorphisms as well as their gene $\times$ environment interactions on post-diagnosis weight gain in breast cancer patients. Our final model shows high discriminatory power with AUCs of 0.90, 0.88, and 0.85 for weight gain at 6,12 , and 18 months post-diagnosis, respectively. We are currently conducting a prospective study of 300 newly diagnosed breast cancer patients to validate 
this predictive model. This risk assessment tool could allow us to identify patients at highest risk for weight gain and target them for weight loss interventions starting at the time of diagnosis. Numerous interventions have been published for this patient population, including diet (De Waard et al, 1993; Loprinzi et al, 1996; Jen et al, 2004; Chlebowski et al, 2006; Hoy et al, 2009), exercise (Schwartz, 2000; Segal et al, 2001), and multidisciplinary (Goodwin et al, 1998; Campbell et al, 2012; Harris et al, 2012) approaches with mixed results and limited long-term data on sustained weight loss. In addition, wide spread implementation of weight loss intervention is less feasible than in a limited population. With a targeted population, the interventions can be more effective, future clinical trials more efficient, and resources more intelligently appropriated. We hope this strategic approach will more effectively prevent the post-diagnosis weight gain seen in breast cancer patients and thereby decrease the associated morbidity and mortality.

\section{ACKNOWLEDGEMENTS}

This study was supported by grants funded by Lynn Sage Foundation (VGK), Dolores Knes Fund (VGK), National Institute of Diabetes and Digestive and Kidney Diseases grants 58785, 79929 and 81913 (CSM), Award Number 1I01CX000422-01A1 from the Clinical Science Research and Development Service of the VA Office of Research and Development (CSM).

\section{REFERENCES}

Aslani A, Smith RC, Allen BJ, Pavlakis N, Levi JA (1999) Changes in body composition during breast cancer chemotherapy with the CMF-regimen. Breast Cancer Res Treat 57(3): 285-290.

Becker T, Schumacher J, Cichon S, Baur MP, Knapp M (2005) Haplotype interaction analysis of unlinked regions. Genet Epidemiol 29(4): 313-322.

Caan BJ, Emond JA, Natarajan L, Castillo A, Gunderson EP, Habel L, Jones L, Newman VA, Rock CL, Slattery ML, Stefanick ML, Sternfeld B, Thomson CA, Pierce JP (2006) Post-diagnosis weight gain and breast cancer recurrence in women with early stage breast cancer. Breast Cancer Res Treat 99(1): $47-57$.

Camoriano JK, Loprinzi CL, Ingle JN, Therneau TM, Krook JE, Veeder MH (1990) Weight change in women treated with adjuvant therapy or observed following mastectomy for node-positive breast cancer. J Clin Oncol 8(8): 1327-1334.

Campbell KL, Lane K, Martin AD, Gelmon KA, McKenzie DC (2007) Resting energy expenditure and body mass changes in women during adjuvant chemotherapy for breast cancer. Cancer Nurs 30(2): 95-100.

Campbell KL, Van Patten CL, Neil SE, Kirkham AA, Gotay CC, Gelmon KA, McKenzie DC (2012) Feasibility of a lifestyle intervention on body weight and serum biomarkers in breast cancer survivors with overweight and obesity. J Acad Nutr Diet 112(4): 559-567.

Chlebowski RT, Aiello E, McTiernan A (2002) Weight loss in breast cancer patient management. J Clin Oncol 20(4): 1128-1143.

Chlebowski RT, Blackburn GL, Thomson CA, Nixon DW, Shapiro A, Hoy MK, Goodman MT, Giuliano AE, Karanja N, McAndrew P, Hudis C, Butler J, Merkel D, Kristal A, Caan B, Michaelson R, Vinciguerra V, Del Prete S, Winkler M, Hall R, Simon M, Winters BL, Elashoff RM (2006) Dietary fat reduction and breast cancer outcome: interim efficacy results from the Women's Intervention Nutrition Study. J Natl Cancer Inst 98(24): 1767-1776.

Cordell HJ (2002) Epistasis: what it means, what it doesn't mean, and statistical methods to detect it in humans. Human Mol Genet 11(20): 2463-2468.

Costa LJ, Varella PC, del Giglio A (2002) Weight changes during chemotherapy for breast cancer. Sao Paulo Med J 120(4): 113-117.

Day R, Ganz PA, Costantino JP, Cronin WM, Wickerham DL, Fisher B (1999) Health-related quality of life and tamoxifen in breast cancer prevention: a report from the National Surgical Adjuvant Breast and Bowel Project P-1 Study. J Clin Oncol 17(9): 2659-2669.
De Waard F, Ramlau R, Mulders Y, De Vries T, Van Waveren S (1993) A feasibility study on weight reduction in obese postmenopausal breast cancer patients. Eur J Cancer Prevent 2(3): 233-238.

Demark-Wahnefried W, Hars V, Conaway MR, Havlin K, Rimer BK, McElveen G, Winer EP (1997a) Reduced rates of metabolism and decreased physical activity in breast cancer patients receiving adjuvant chemotherapy. Am J Clin Nutr 65(5): 1495-1501.

Demark-Wahnefried W, Rimer BK, Winer EP (1997b) Weight gain in women diagnosed with breast cancer. J Am Diet Assoc 97(5): 519-526,529; quiz 527-8.

Edwards TL, Velez Edwards DR, Villegas R, Cohen SS, Buchowski MS, Fowke JH, Schlundt D, Long J, Cai Q, Zheng W, Shu XO, Hargreaves MK, Smith J, Williams SM, Signorello LB, Blot WJ, Matthews CE (2012) HTR1B, ADIPOR1, PPARGC1A, and CYP19A1 and obesity in a cohort of Caucasians and African Americans: an evaluation of gene-environment interactions and candidate genes. Am J Epidemiol 175(1): 11-21.

Filippi E, Sentinelli F, Romeo S, Arca M, Berni A, Tiberti C, Verrienti A, Fanelli M, Fallarino M, Sorropago G, Baroni MG (2005) The adiponectin gene $\mathrm{SNP}+276 \mathrm{G}>\mathrm{T}$ associates with early-onset coronary artery disease and with lower levels of adiponectin in younger coronary artery disease patients (age < or =50 years). J Mol Med 83(9): 711-719.

Fox CS, Heard-Costa NL, Vasan RS, Murabito JM, D’Agostino Sr. RB, Atwood LD, Framingham Heart S (2005) Genomewide linkage analysis of weight change in the Framingham Heart Study. J Clin Endocrinol Metab 90(6): 3197-3201.

Freedman RJ, Aziz N, Albanes D, Hartman T, Danforth D, Hill S, Sebring N, Reynolds JC, Yanovski JA (2004) Weight and body composition changes during and after adjuvant chemotherapy in women with breast cancer. J Clin Endocrinol Metab 89(5): 2248-2253.

Gelman A, Jakulin A, Pittau MG, Su YS (2008) A weakly informative default prior distribution for logistic and other regression models. Ann Appl Stat 2(4): 1360-1383.

Gloeckler Ries LA, Reichman ME, Lewis DR, Hankey BF, Edwards BK (2003) Cancer survival and incidence from the Surveillance, Epidemiology, and End Results (SEER) program. The oncologist 8(6): 541-552.

Goodwin P, Esplen MJ, Butler K, Winocur J, Pritchard K, Brazel S, Gao J, Miller A (1998) Multidisciplinary weight management in locoregional breast cancer: results of a phase II study. Breast Cancer Res Treat 48(1): 53-64.

Goodwin PJ, Ennis M, Pritchard KI, McCready D, Koo J, Sidlofsky S, Trudeau M, Hood N, Redwood S (1999) Adjuvant treatment and onset of menopause predict weight gain after breast cancer diagnosis. J Clin Oncol 17(1): 120-129.

Grant SF, Li M, Bradfield JP, Kim CE, Annaiah K, Santa E, Glessner JT, Casalunovo T, Frackelton EC, Otieno FG, Shaner JL, Smith RM, Imielinski M, Eckert AW, Chiavacci RM, Berkowitz RI, Hakonarson H (2008) Association analysis of the FTO gene with obesity in children of Caucasian and African ancestry reveals a common tagging SNP. PLoS One 3(3): e1746.

Gu K, Chen X, Zheng Y, Chen Z, Zheng W, Lu W, Shu XO (2010) Weight change patterns among breast cancer survivors: results from the Shanghai breast cancer survival study. Cancer Causes Control 21(4): 621-629.

Han HS, Lee KW, Kim JH, Kim SW, Kim IA, Oh DY, Im SA, Bang SM, Lee JS (2009) Weight changes after adjuvant treatment in Korean women with early breast cancer. Breast Cancer Res Treat 114(1): $147-153$.

Han LY, Wu QH, Jiao ML, Hao YH, Liang LB, Gao LJ, Legge DG, Quan H, Zhao MM, Ning N, Kang Z, Sun H (2011) Associations between singlenucleotide polymorphisms $(+45 \mathrm{~T}>\mathrm{G},+276 \mathrm{G}>\mathrm{T},-11377 \mathrm{C}>\mathrm{G}$, $-11391 \mathrm{G}>\mathrm{A}$ ) of adiponectin gene and type 2 diabetes mellitus: a systematic review and meta-analysis. Diabetologia 54(9): 2303-2314.

Hara K, Boutin P, Mori Y, Tobe K, Dina C, Yasuda K, Yamauchi T, Otabe S, Okada T, Eto K, Kadowaki H, Hagura R, Akanuma Y, Yazaki Y, Nagai R, Taniyama M, Matsubara K, Yoda M, Nakano Y, Tomita M, Kimura S, Ito C, Froguel P, Kadowaki T (2002) Genetic variation in the gene encoding adiponectin is associated with an increased risk of type 2 diabetes in the Japanese population. Diabetes 51(2): 536-540.

Harris MN, Swift DL, Myers VH, Earnest CP, Johannsen NM, Champagne CM, Parker BD, Levy E, Cash KC, Church TS (2012) Cancer Survival Through Lifestyle Change (CASTLE): a Pilot Study of Weight Loss.

Int J Behav Med; e-pub ahead of print 26 April 2012.

He B, Pan Y, Zhang Y, Bao Q, Chen L, Nie Z, Gu L, Xu Y, Wang S (2011) Effects of genetic variations in the adiponectin pathway genes on 
the risk of colorectal cancer in the Chinese population. BMC Med Genet 12: 94 .

Hegener HH, Lee IM, Cook NR, Ridker PM, Zee RY (2006) Association of adiponectin gene variations with risk of incident myocardial infarction and ischemic stroke: a nested case-control study. Clin Chem 52(11): 2021-2027.

Heid IM, Wagner SA, Gohlke H, Iglseder B, Mueller JC, Cip P, Ladurner G, Reiter R, Stadlmayr A, Mackevics V, Illig T, Kronenberg F, Paulweber B (2006) Genetic architecture of the APM1 gene and its influence on adiponectin plasma levels and parameters of the metabolic syndrome in 1,727 healthy Caucasians. Diabetes 55(2): 375-384.

Heideman WH, Russell NS, Gundy C, Rookus MA, Voskuil DW (2009) The frequency, magnitude and timing of post-diagnosis body weight gain in Dutch breast cancer survivors. Eur J Cancer 45(1): 119-126.

Hein R, Beckmann L, Chang-Claude J (2009) Comparison of different haplotype-based association methods for gene-environment (GxE) interactions in case-control studies when haplotype-phase is ambiguous. Hum Hered 68(4): 252-267.

Hinney A, Nguyen TT, Scherag A, Friedel S, Bronner G, Muller TD, Grallert H, Illig T, Wichmann HE, Rief W, Schafer H, Hebebrand J (2007) Genome wide association (GWA) study for early onset extreme obesity supports the role of fat mass and obesity associated gene (FTO) variants. PLoS One 2(12): e1361.

Hoy MK, Winters BL, Chlebowski RT, Papoutsakis C, Shapiro A, Lubin MP, Thomson CA, Grosvenor MB, Copeland T, Falk E, Day K, Blackburn GL (2009) Implementing a low-fat eating plan in the Women's Intervention Nutrition Study. J Am Diet Assoc 109(4): 688-696.

Hsiao TJ, Wu LS, Huang SY, Lin E (2010) A common variant in the adiponectin gene on weight loss and body composition under sibutramine therapy in obesity. Clin Pharmacol 2: 105-110.

Ingram C, Brown JK (2004) Patterns of weight and body composition change in premenopausal women with early stage breast cancer: has weight gain been overestimated? Cancer Nurs 27(6): 483-490.

Irwin ML, McTiernan A, Baumgartner RN, Baumgartner KB, Bernstein L, Gilliland FD, Ballard-Barbash R (2005) Changes in body fat and weight after a breast cancer diagnosis: influence of demographic, prognostic, and lifestyle factors. J Clin Oncol 23(4): 774-782.

Janssens AC, Moonesinghe R, Yang Q, Steyerberg EW, van Duijn CM, Khoury MJ (2007) The impact of genotype frequencies on the clinical validity of genomic profiling for predicting common chronic diseases. Genet Med 9(8): 528-535.

Jen KL, Djuric Z, DiLaura NM, Buison A, Redd JN, Maranci V, Hryniuk WM (2004) Improvement of metabolism among obese breast cancer survivors in differing weight loss regimens. Obes Res 12(2): 306-312.

Kaklamani V, Yi N, Sadim M, Siziopikou K, Zhang K, Xu Y, Tofilon S, Agarwal S, Pasche B, Mantzoros C (2011a) The role of the fat mass and obesity associated gene (FTO) in breast cancer risk. BMC Med Genet 12: 52 .

Kaklamani V, Yi N, Zhang K, Sadim M, Offit K, Oddoux C, Ostrer H, Mantzoros C, Pasche B (2011b) Polymorphisms of ADIPOQ and ADIPOR1 and prostate cancer risk. Metabolism 60(9): 1234-1243.

Kaklamani VG, Sadim M, Hsi A, Offit K, Oddoux C, Ostrer H, Ahsan H, Pasche B, Mantzoros C (2008a) Variants of the adiponectin and adiponectin receptor 1 genes and breast cancer risk. Cancer Res 68(9): 3178-3184.

Kaklamani VG, Wisinski KB, Sadim M, Gulden C, Do A, Offit K, Baron JA, Ahsan H, Mantzoros C, Pasche B (2008b) Variants of the adiponectin (ADIPOQ) and adiponectin receptor 1 (ADIPOR1) genes and colorectal cancer risk. JAMA 300(13): 1523-1531.

Kao CH, Zeng ZB (2002) Modeling epistasis of quantitative trait loci using Cockerham's model. Genetics 160(3): 1243-1261.

Kroenke CH, Chen WY, Rosner B, Holmes MD (2005) Weight, weight gain, and survival after breast cancer diagnosis. J Clin Oncol 23(7): 1370-1378.

Kumar NB, Allen K, Cantor A, Cox CE, Greenberg H, Shah S, Lyman GH (1997) Weight gain associated with adjuvant tamoxifen therapy in stage I and II breast cancer: fact or artifact? Breast Cancer Res Treat 44(2): $135-143$.

Kutynec CL, McCargar L, Barr SI, Hislop TG (1999) Energy balance in women with breast cancer during adjuvant treatment. J Am Diet Assoc 99(10): 1222-1227.
Kwee LC, Epstein MP, Manatunga AK, Duncan R, Allen AS, Satten GA (2007) Simple methods for assessing haplotype-environment interactions in case-only and case-control studies. Genet Epidemiol 31(1): 75-90.

Lake SL, Lyon H, Tantisira K, Silverman EK, Weiss ST, Laird NM, Schaid DJ (2003) Estimation and tests of haplotype-environment interaction when linkage phase is ambiguous. Hum Hered 55(1): 56-65.

Lankester KJ, Phillips JE, Lawton PA (2002) Weight gain during adjuvant and neoadjuvant chemotherapy for breast cancer: an audit of 100 women receiving FEC or CMF chemotherapy. Clin Oncol 14(1): 64-67.

Litton JK, Gonzalez-Angulo AM, Warneke CL, Buzdar AU, Kau SW, Bondy M, Mahabir S, Hortobagyi GN, Brewster AM (2008) Relationship between obesity and pathologic response to neoadjuvant chemotherapy among women with operable breast cancer. J Clin Oncol 26(25): 4072-4077.

Liu F, He Z, Deng S, Zhang H, Li N, Xu J (2011) Association of adiponectin gene polymorphisms with the risk of ischemic stroke in a Chinese Han population. Mol Biol Rep 38(3): 1983-1988.

Loi S, Milne RL, Friedlander ML, McCredie MR, Giles GG, Hopper JL, Phillips KA (2005) Obesity and outcomes in premenopausal and postmenopausal breast cancer. Cancer Epidemiol Biomarkers Prev 14(7): 1686-1691.

Loos RJ, Ruchat S, Rankinen T, Tremblay A, Perusse L, Bouchard C (2007) Adiponectin and adiponectin receptor gene variants in relation to resting metabolic rate, respiratory quotient, and adiposity-related phenotypes in the Quebec Family Study. Am J Clin Nutr 85(1): 26-34.

Loprinzi CL, Athmann LM, Kardinal CG, O'Fallon JR, See JA, Bruce BK, Dose AM, Miser AW, Kern PS, Tschetter LK, Rayson S (1996) Randomized trial of dietician counseling to try to prevent weight gain associated with breast cancer adjuvant chemotherapy. Oncology 53(3): $228-232$.

Mather KJ, Christophi CA, Jablonski KA, Knowler WC, Goldberg RB, Kahn SE, Spector T, Dastani Z, Waterworth D, Richards JB, Funahashi T, Pi-Sunyer FX, Pollin TI, Florez JC, Franks PW. for the Diabetes Prevention Program Research G (2012) Common variants in genes encoding adiponectin (ADIPOQ) and its receptors (ADIPOR1/2), adiponectin concentrations, and diabetes incidence in the Diabetes Prevention Program. Diabet Med 29(12): 1579-1588.

Menzaghi C, Ercolino T, Di Paola R, Berg AH, Warram JH, Scherer PE, Trischitta V, Doria A (2002) A haplotype at the adiponectin locus is associated with obesity and other features of the insulin resistance syndrome. Diabetes 51(7): 2306-2312.

Mtiraoui N, Ezzidi I, Turki A, Chaieb A, Mahjoub T, Almawi WY (2012) Single-nucleotide polymorphisms and haplotypes in the adiponectin gene contribute to the genetic risk for type 2 diabetes in Tunisian Arabs. Diab Res Clin Pract 97(2): 290-297.

Rampersaud E, Mitchell BD, Pollin TI, Fu M, Shen H, O'Connell JR, Ducharme JL, Hines S, Sack P, Naglieri R, Shuldiner AR, Snitker S (2008) Physical activity and the association of common FTO gene variants with body mass index and obesity. Arch Int Med 168(16): 1791-1797.

Rock CL, Demark-Wahnefried W (2002) Nutrition and survival after the diagnosis of breast cancer: a review of the evidence. J Clin Oncol 20(15): 3302-3316.

Saquib N, Flatt SW, Natarajan L, Thomson CA, Bardwell WA, Caan B, Rock CL, Pierce JP (2007) Weight gain and recovery of pre-cancer weight after breast cancer treatments: evidence from the women's healthy eating and living (WHEL) study. Breast Cancer Res Treat 105(2): $177-186$.

Schwartz AL (2000) Exercise and weight gain in breast cancer patients receiving chemotherapy. Cancer Pract 8(5): 231-237.

Segal R, Evans W, Johnson D, Smith J, Colletta S, Gayton J, Woodard S, Wells G, Reid R (2001) Structured exercise improves physical functioning in women with stages I and II breast cancer: results of a randomized controlled trial. J Clin Oncol 19(3): 657-665.

Siitonen N, Pulkkinen L, Mager U, Lindstrom J, Eriksson JG, Valle TT, Hamalainen H, Ilanne-Parikka P, Keinanen-Kiukaanniemi S, Tuomilehto J, Laakso M, Uusitupa M (2006) Association of sequence variations in the gene encoding adiponectin receptor 1 (ADIPOR1) with body size and insulin levels. The Finnish Diabetes Prevention Study. Diabetologia 49(8): 1795-1805.

Silventoinen K, Kaprio J (2009) Genetics of tracking of body mass index from birth to late middle age: evidence from twin and family studies. Obes Facts 2(3): 196-202.

Soccio T, Zhang YY, Bacci S, Mlynarski W, Placha G, Raggio G, Di Paola R, Marucci A, Johnstone MT, Gervino EV, Abumrad NA, Klein S, Trischitta V, Doria A (2006) Common haplotypes at the adiponectin receptor 1 
(ADIPOR1) locus are associated with increased risk of coronary artery disease in type 2 diabetes. Diabetes 55(10): 2763-2770.

Stumvoll M, Tschritter O, Fritsche A, Staiger H, Renn W, Weisser M, Machicao F, Haring H (2002) Association of the T-G polymorphism in adiponectin (exon 2) with obesity and insulin sensitivity: interaction with family history of type 2 diabetes. Diabetes 51(1): 37-41.

Thorleifsson G, Walters GB, Gudbjartsson DF, Steinthorsdottir V, Sulem P, Helgadottir A, Styrkarsdottir U, Gretarsdottir S, Thorlacius S, Jonsdottir I, Jonsdottir T, Olafsdottir EJ, Olafsdottir GH, Jonsson T, Jonsson F, Borch-Johnsen K, Hansen T, Andersen G, Jorgensen T, Lauritzen T, Aben KK, Verbeek AL, Roeleveld N, Kampman E, Yanek LR, Becker LC, Tryggvadottir L, Rafnar T, Becker DM, Gulcher J, Kiemeney LA, Pedersen O, Kong A, Thorsteinsdottir U, Stefansson K (2009) Genome-wide association yields new sequence variants at seven loci that associate with measures of obesity. Nat Genet 41(1): 18-24.

Ukkola O, Santaniemi M, Rankinen T, Leon AS, Skinner JS, Wilmore JH, Rao DC, Bergman R, Kesaniemi YA, Bouchard C (2005) Adiponectin polymorphisms, adiposity and insulin metabolism: HERITAGE family study and Oulu diabetic study. Ann Med 37(2): 141-150.

van Hoek M, Dehghan A, Witteman JC, van Duijn CM, Uitterlinden AG, Oostra BA, Hofman A, Sijbrands EJ, Janssens AC (2008) Predicting type 2 diabetes based on polymorphisms from genome-wide association studies: a population-based study. Diabetes 57(11): 3122-3128.

Vance V, Mourtzakis M, McCargar L, Hanning R (2011) Weight gain in breast cancer survivors: prevalence, pattern and health consequences. Obes Rev 12(4): 282-294.

Vasseur F, Helbecque N, Dina C, Lobbens S, Delannoy V, Gaget S, Boutin P, Vaxillaire M, Lepretre F, Dupont S, Hara K, Clement K, Bihain B, Kadowaki T, Froguel P (2002) Single-nucleotide polymorphism haplotypes in the both proximal promoter and exon 3 of the APM1 gene modulate adipocyte-secreted adiponectin hormone levels and contribute to the genetic risk for type 2 diabetes in French Caucasians. Hum Mol Genet 11(21): 2607-2614.
Wardle J, Carnell S, Haworth CM, Farooqi IS, O'Rahilly S, Plomin R (2008) Obesity associated genetic variation in FTO is associated with diminished satiety. J Clin Endocrinol Metab 93(9): 3640-3643.

Williamson DF (1993) Descriptive epidemiology of body weight and weight change in U.S. adults. Ann Int Med 119(7 Pt 2): 646-649.

Williamson DF, Kahn HS, Byers T (1991) The 10-y incidence of obesity and major weight gain in black and white US women aged 30-55 y. Am J Clin Nutr 53(6 Suppl): 1515S-1518S.

Yang WS, Chuang LM (2006) Human genetics of adiponectin in the metabolic syndrome. J Mol Med 84(2): 112-121.

Yang Y, Zhang F, Ding R, Wang Y, Lei H, Hu D (2012) Association of ADIPOQ gene polymorphisms and coronary artery disease risk: a meta-analysis based on 12465 subjects. Thrombosis Res 130(1): $58-64$.

Yi NJ, Banerjee S (2009) Hierarchical Generalized Linear Models for Multiple Quantitative Trait Locus Mapping. Genetics 181(3): 1101-1113.

Yi NJ, Xu SH (2008) Bayesian LASSO for quantitative trait loci mapping. Genetics 179(2): 1045-1055.

Zhang H, Mo X, Hao Y, Gu D (2012) Association between polymorphisms in the adiponectin gene and cardiovascular disease: a meta-analysis. $B M C$ Med Genet 13: 40.

Zhao J, Bradfield JP, Li M, Wang K, Zhang H, Kim CE, Annaiah K, Glessner JT, Thomas K, Garris M, Frackelton EC, Otieno FG, Shaner JL, Smith RM, Chiavacci RM, Berkowitz RI, Hakonarson H, Grant SF (2009) The role of obesity-associated loci identified in genome-wide association studies in the determination of pediatric BMI. Obesity 17(12): 2254-2257.

This work is published under the standard license to publish agreement. After 12 months the work will become freely available and the license terms will switch to a Creative Commons AttributionNonCommercial-Share Alike 3.0 Unported License.

Supplementary Information accompanies this paper on British Journal of Cancer website (http://www.nature.com/bjc) 